\title{
SUJEITOS DA EDUCAÇÃO DE JOVENS E ADULTOS E OS SENTIDOS ATRIBUÍDOS AO LIVRO DIDÁTICO
}

\author{
SANTOS, Cheila Dias ${ }^{1}$ \\ FERNANDES, Andrea da Paixão ${ }^{2}$
}

\section{RESUMO}

O presente artigo apresenta um recorte da pesquisa realizada com os alunos da Educação de Jovens e Adultos (EJA), da Rede Pública Municipal de Educação de São Gonçalo, município localizado na Região Metropolitana do Estado do Rio de Janeiro. A pesquisa aborda a importância e o uso do Livro Didático (LD) para esses sujeitos. Para isso, a pesquisa procurou investigar os sentidos atribuídos pelos estudantes do Grupo I, Fases 1 e 2 dessa modalidade a esse recurso didático de forma geral e, concomitante, também a questão da aplicabilidade do LD "EJA Moderna, volume I, do Programa Nacional do Livro Didático para a EJA (PNLD/EJA) adotado por essa rede de ensino. A pesquisa assim configurada traz 0 entendimento de que para suprir as necessidades dos educandos e efetivamente cumprir o seu papel de formação e informação é necessário que o LD seja concebido considerando-se que os conteúdos nele presentes estejam contextualizados de acordo com o contexto social do aluno,com vistas à aquisição dos bens socioculturais, leia-se, à cultura letrada a que todo cidadão tem direito.

Palavras-Chave: Educação de Jovens e Adultos; Livro Didático; Representações Sociais.

\begin{abstract}
This article presents a review of the research carried out with the students of the Youth and Adult Education of the Municipal Department Education of São Gonçalo, a municipality located in the Metropolitan Region of the State of Rio de Janeiro, regarding the importance and use of the Didactic Book (LD) for these subjects. For this, the research sought to investigate the meanings attributed by the students of Group I, Phases 1 and 2 of this modality to this didactic resource in a general way and, concurrently, also the question of the applicability of the LD "EJA Moderna, volume I, of the National Program Of the Textbook for the EJA (PNLD / EJA) adopted by this teaching network. The research thus configured, brings the understanding that to meet the needs of learners and effectively fulfill their role of training and information it is necessary that the LD is conceived considering that the contents present in it are contextualized according to the social context of the Student, with a view to the acquisition of socio-cultural goods, read, to the learned culture to which every citizen is entitled.
\end{abstract}

\footnotetext{
${ }^{1}$ Mestre em Ensino de Educação Básica (PPGEB/CAp-UERJ); professora da Rede Municipal de Educação de São Gonçalo. e-mail: cheilasaid@yahoo.com.br

${ }^{2}$ Professora Adjunta da Universidade do Estado do Rio de Janeiro, Instituto de Aplicação Fernando Rodrigues da Silveira (CAp-UERJ). e-mail: andreaf@uerj.br
} 
DOI: $10.12957 /$ e-mosaicos.2018.38651

KeYworDS: Youth and Adult Education; Didactic Book; Socials Representations.

\section{DiÁLOGO INICIAL}

Nesse artigo, apresentamos resultados de pesquisa de mestrado em que foi analisado o uso de materiais didáticos para a modalidade Educação de Jovens e Adultos (EJA), tendo como referência o livro didático disponibilizado pelo Programa Nacional de Livro Didático (PNLD) para a educação de jovens e adultos (PNLD/EJA). Os levantamentos foram realizados junto a escolas da rede municipal de educação de São Gonçalo/RJ que oferecem a modalidade EJA. A pesquisa procurou caracterizar Material Didático (MD) e as formas de concebê-lo. Foi considerada a existência de uma diversidade de materiais que podem auxiliar o trabalho docente no desenvolvimento do processo de ensino-aprendizagem, embora o recorte analisado tenha tido como centro o uso do livro didático.

O LD pode ser considerado um objeto cultural cuja materialidade visa facilitar o processo de assimilação dos conteúdos curriculares, uma vez que o mesmo expressa uma preocupação com as matrizes curriculares. No entanto, para que o LD cumpra o seu papel é preciso que o mesmo seja concebido privilegiando os conteúdos que dialoguem com a diversidade que caracteriza o campo da EJA, com suas especificidades e regionalismos. Precisa apresentar linguagem que, efetivamente, dialogue com os estudantes da EJA e suas realidades, com uso de linguagem clara e sem, contudo, deixar de ser um instrumento instigante, prazeroso.

Para esse artigo, consideramos dados que se refiram ao uso do livro didático junto a estudantes da rede pública municipal de São Gonçalo, destacando-se a necessidade de que o livro didático, bem como os demais materiais didáticos adotados dialoguem com os contextos de vida e campos de interesse dos estudantes da modalidade EJA.

\section{USOS DO LIVRO DIDÁTICO E CONTRIBUIÇÕES PARA O PROCESSO DE ENSINO- APRENDIZAGEM}

A partir da compreensão de que os materiais didáticos devem considerar as questões cotidianas que sejam representativas do contexto em que o aluno está inserido e as potencialidades de se usar socialmente o conteúdo proposto, a pesquisa desenvolvida teve por objetivo conhecer a importância atribuída pelos sujeitos da EJA (estudantes e professores) ao Livro Didático.

Ao se estruturar um material didático, a relação dos campos conceituais e sua aplicabilidade prática devem estar diretamente relacionadas. A afirmação de Freire (1996) de que "ensinar não é transferir conhecimento, mas criar as possibilidades para a sua produção ou a sua construção" (FREIRE, 1996, p. 21), fundamenta a 
DOI: $10.12957 /$ e-mosaicos.2018.38651

necessidade de que, ao ensinar (que deve ser um processo dialógico), professores devem valorizar os saberes da vida, dos contextos cotidianos em que transitam os estudantes. Dessa forma, ensinar e aprender são vias de mão dupla.

Antes de caracterizar o livro didático, faz-se necessário definir material didático como o conjunto de suportes que buscam auxiliar o trabalho docente no desenvolvimento do processo de ensino e de aprendizagem. Dos materiais de uso contínuo em sala de aula e de mais simples e de fácil manuseio como até os de maior complexidade e que requerem o uso de modernas tecnologias educacionais, 0 uso de determinado MD só se justifica se for contribuir de forma significativa para o desenvolvimento do processo ensino-aprendizagem.

De acordo com Rondelli (2007, p. 6)

O material didático representa uma das principais relações que o aluno estabelece com aquilo que aprende. É um meio importante de interação entre o professor e o aluno, pois é uma forma de orientar o aluno em um oceano de possibilidades. Por isso, o material didático precisa ser de ótima qualidade, ter uma apresentação impecável, revelar a metodologia implícita no processo de elaboração, dar conta dos temas abordados de modo claro, trazer um roteiro rico em possibilidades de leituras, pesquisas e atividades, além de estimular o aluno a ter o prazer de voltar para ali; ou seja, seduzi-lo. Produzir material didático é uma tarefa complexa, que demanda uma equipe com excelente formação acadêmica e cultural (RONDELLI, 2007, p. $6)$.

Com o livro didático não é diferente. Considerado como um objeto cultural cuja materialidade visa facilitar o processo de assimilação dos conteúdos curriculares, para que cumpra o seu papel é preciso que seja concebido privilegiando os conteúdos, tratando-os com clareza e sem, contudo, deixar de ser um instrumento instigante, prazeroso. Diante disso, o material de cunho didático e, dentre eles, o livro didático, deve ser pensado considerando a familiaridade com os conteúdos abordados, a adequação metodológica, a qualidade não só visual e gráfica e, também as potencialidades de representar enriquecimento de leitura e estímulo à interatividade entre o aluno e o professor.

No cenário nacional, a criação do Programa Nacional do Livro Didático, em 1985, e do PNLD/EJA em 2009, possibilitou maior acesso ao livro como um dos materiais didáticos a serem utilizados em sala de aula e assegurou a todos os estudantes de escolas públicas o recebimento desse material. Contudo, é importante considerar que, como todo material didático, o livro apresenta seus limites, sobretudo ao ser um material estruturado para todo o território nacional, com toda diversidade que caracteriza cada região brasileira. Diante disso, é de extrema validade que professores e estudantes façam uso crítico do livro como material 
DOI: $10.12957 /$ e-mosaicos.2018.38651

didático, sobretudo no campo da EJA, onde os saberes do cotidiano do povo se destacam de forma relevante.

\section{REVELAÇÕES DA PESQUISA - DA METODOLOGIA AOS RESULTADOS}

A pesquisa a que fazemos referência foi realizada junto a estudantes do Grupo I da modalidade Educação de Jovens e Adultos, distribuídos nas Fases 1 e 2 do primeiro segmento, em três escolas da Rede Municipal de Educação de São Gonçalo, em dois momentos distintos, priorizando duas abordagens metodológicas: inicialmente, através do uso exploratório da técnica de associação livre de palavras (ABRIC, 2001), constantes nos questionários, complementada pelo diário de campo e, posteriormente, utilizando-se, para tratamento dos dados coletados a Análise de Conteúdo (AC) referenciada em Bardin (2002) e Franco (2004).

As escolas pesquisadas foram escolhidas tomando-se por critério o IDHM $^{3}$ dos bairros em que as mesmas estão localizadas. Assim, as instituições escolares lócus dessa pesquisa foram nomeadas como IE1, IE2 e IE3 ${ }^{4}$ e obtiveram respectivamente os seguintes IDHM: médio, bom e muito bom.

A opção pela aplicação dos questionários foi a de proceder ao levantamento do perfil dos sujeitos participantes da pesquisa, identificando-os e contextualizandoos socialmente. Tais instrumentos permitem a captação dos indícios contribuindo para a análise das representações e dos sentidos dos respondentes acerca do objeto a ser pesquisado. No entanto, é preciso observar as limitações desse importante instrumento metodológico de pesquisa. Nesse sentido, segundo Fernandes (2012, p. 235):

Cabe ressaltar que os questionários são instrumentos privilegiados na pesquisa em RS, não só porque, a partir de uma análise quantitativa, permitem organizar as respostas, mas também porque evidenciam aspectos que definem a população pesquisada e explicitam as posições dos grupos estudados. Contudo, não se pode desconsiderar que o questionário como instrumento metodológico da pesquisa também tem seus limites.

Os questionários foram elaborados tendo em sua composição perguntas abertas e fechadas. As questões fechadas e que compuseram o primeiro bloco do instrumento, caracterizavam de forma geral o perfil dos participantes da pesquisa (identificação, idade, sexo, profissão e local em que estuda), ao passo que o

${ }^{3}$ O Índice de Desenvolvimento Humano Municipal (IDHM) é uma medida adaptada ao nível municipal desde 1998 com o objetivo de mensurar o desenvolvimento humano de cada município. Fonte: PNUD/BRASIL. Acesso: Maio/2015.

${ }^{4}$ IE- Instituição Escolar 1, Instituição Escolar 2 e Instituição Escolar 3. 


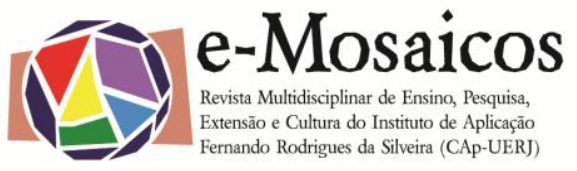

DOI: $10.12957 /$ e-mosaicos.2018.38651

segundo bloco trouxe questões abertas e que tinham por objetivo captar e identificar os sentidos atribuídos pelos alunos à EJA e ao LD.

Nessa pesquisa, mais do que a quantidade de respondentes, preocupamo-nos com sua representatividade com base na caracterização e no contexto da EJA nas escolas pesquisadas da SEMED/SG. Nesse sentido, é preciso considerar que, além da EJA ser um campo dotado de complexidades, o contexto sócio, político e econômico da época de desenvolvimento da pesquisa dificultou a permanência dos educandos nas salas de aula, pouco diferindo do primeiro para o segundo segmento dessa modalidade. Tais dificuldades se igualam tanto em um, quanto em outro segmento. Referimo-nos à questão da frequência dos educandos seguida quase sempre da evasão, questão essa histórica, se considerarmos que o contexto dos alunos da EJA é permanentemente de entrada e de saída da escola ao longo de suas vidas, ora por questões de sobrevivência (quando é preciso optar pela permanência no trabalho), ora por questões familiares (traduzida na necessidade de cuidar de algum familiar), ora por questões outras que vão desde a socialização com os colegas mais jovens até a dificuldade em assimilar os conteúdos propostos, o que colabora para postergar a reentrada na escola sempre tardiamente.

Com os dados obtidos na investigação com os educandos, foi possível caracterizar o perfil dos mesmos a partir do contexto encontrado. Assim, foi possível observar que no universo de 24 alunos participantes, a grande maioria (15) é do sexo feminino com idades variando entre 35 e 84 anos, com predominância de 9 alunos na faixa etária de 50 anos. Do total de alunos pesquisados 13 são casados, 7 são solteiros, 1 é divorciado e 3 são viúvos. Desse quantitativo, 20 têm filhos.

Em relação ao item trabalho, a pesquisa revelou que 17 alunos exercem atividade remunerada, desses apenas 10 trabalham com carteira assinada, ao passo que dentre os alunos restantes 5 são aposentados e 2 trabalham em casa.

Por meio da aplicação exploratória da técnica de associação livre de palavras, foi solicitado aos alunos a escreverem espontaneamente cinco palavras que lhes viessem à mente ao ouvirem/lerem a evocação "O Livro Didático da EJA para você é..."

Na construção do corpus dessa pesquisa, houve a preocupação não apenas de relatar e descrever os dados coletados, mas, principalmente, de analisar as representações sociais que envolvem o fenômeno investigado. Para isso, foram utilizados como estratégias metodológicas os instrumentos já anteriormente descritos: questionários, associação livre de palavras, assim como os registros do diário de campo. Após essa etapa, passamos à fase de tratamento e análise dos dados coletados nos questionários direcionados aos estudantes e professores participantes da pesquisa. Foram coletadas um total de 50 expressões para o grupo de alunos, a partir dos termos indutores direcionados a cada um dos participantes da pesquisa buscou-se captar e analisar os sentidos que os mesmos atribuem ao livro didático. Dessa maneira, no intuito de compor o corpus, foi preciso observar três 
DOI: $10.12957 /$ e-mosaicos.2018.38651

etapas para se proceder à análise de conteúdo propriamente dita, os quais de acordo com a orientação de Bardin (2002) são: 1) a pré-análise; 2) a exploração do material; 3) o tratamento dos resultados, a inferência e a interpretação.

Esta etapa exigiu uma leitura exaustiva sobre o material coletado durante a pesquisa nas escolas com o objetivo de tratar as palavras e expressões que comporiam o corpus. Com esses dados tabulados em mãos, foi elaborada uma planilha no Excel 2013 para categorizar as evocações relacionadas ao objeto da pesquisa a partir do primeiro termo indutor direcionado aos alunos, seguida de quadro com a justificativa. As palavras oriundas das evocações dos sujeitos da pesquisa, por sua vez, deram origem à elaboração de um dicionário de sinonímias.

ESQUEMA DA ANÁLISE CATEGORIAL-TEMÁTICA - "O Livro Didático da EJA para você é..."do Instrumento direcionado ao aluno:

\begin{tabular}{|c|c|c|c|c|}
\hline $\begin{array}{l}\text { CATEGORIA } \\
\text { TEMÁTICA }\end{array}$ & SUBCATEGORIA & FREQUÊNCIA & $\boldsymbol{\Sigma}$ & JUSTIFICATIVA \\
\hline AJUDA-AUXİLIO & $\begin{array}{l}\text { ajuda } \\
\text { ajuda pra ler e } \\
\text { escrever } \\
\text { ajuda a aprender } \\
\text { ajuda para } \\
\text { aprender } \\
\text { auxílio } \\
\text { melhorar a escrita } \\
\text { para aprender a ler }\end{array}$ & $\begin{array}{l}15 \\
8 \\
3 \\
3 \\
3 \\
1 \\
1\end{array}$ & 34 & $\begin{array}{l}\text { O livro ajuda a } \\
\text { aprender a ler e a } \\
\text { escrever. }\end{array}$ \\
\hline $\begin{array}{l}\text { IMPORTANTE- } \\
\text { NECESSÁRIO }\end{array}$ & $\begin{array}{l}\text { importante } \\
\text { necessário }\end{array}$ & $\begin{array}{l}13 \\
7\end{array}$ & 20 & $\begin{array}{lr}\text { "Pra" } & \text { ajudar } \\
\text { "agente" } & \text { a } \\
\text { aprender. } & \end{array}$ \\
\hline $\begin{array}{l}\text { DIFÍCIL- } \\
\text { DIFICULDADE }\end{array}$ & difícil & 15 & 15 & $\begin{array}{l}\text { Porque tenho } \\
\text { dificuldade para ler } \\
\text { e entender os } \\
\text { exercícios do livro. }\end{array}$ \\
\hline DIREITO & direito & 5 & 8 & Porque ter o livro é \\
\hline
\end{tabular}


DOI: $10.12957 /$ e-mosaicos.2018.38651

\begin{tabular}{|c|c|c|c|c|}
\hline & $\begin{array}{l}\text { não tenho, não } \\
\text { ganhei, } \\
\text { bom } \\
\text { não tem }\end{array}$ & $\begin{array}{l}1 \\
1\end{array}$ & & um direito nosso. \\
\hline RECURSO & Bom & 6 & 6 & $\begin{array}{lr}\text { "Pra" } & \text { ajudar } \\
\text { "agente" } & \text { a } \\
\text { aprender. } & \end{array}$ \\
\hline
\end{tabular}

A partir da análise dos dados, foi possível criar as seguintes categorias: ajudaauxílio, difícil-dificuldade, direito, importante-necessário, recurso com destaque para as palavras que foram evocadas apresentando uma frequência maior como é o caso das evocações: "ajuda (15, ), difícil (15), importante (13), necessário (7)"como bem ilustra a tabela anterior.

Essas categorias representam uma aproximação com o objeto dessa pesquisa e as respectivas subcategorias revelam o valor simbólico que o Livro Didático representa para o aluno dessa modalidade. As evocações expressas nas subcategorias com maior número de vezes evocadas, que por sua vez constituem a categoria temática ajuda-auxílio como é o caso da palavra "ajuda" (15 vezes evocada), assim como as evocações "importante" (13) e "necessário" (7) são representativas e reveladoras dos sentidos que os alunos da EJA têm sobre o valor social do Livro Didático ainda mais, se considerarmos que a grande maioria dos respondentes não tiveram acesso a esse instrumento.

Dos vinte e quatro estudantes, distribuídos nas três escolas pesquisadas, que responderam ao questionário, quando perguntados a respeito do que significava 0 Livro Didático para cada um deles, as respostas mais recorrentes advém do fato de que a aprendizagem da leitura e da escrita possa estar associada a ter a posse do livro, como nos mostra as evocações "ajuda a aprender/me/horar a escrita/para aprender a ler/ajuda pra ler e escrever". Essa referência esteve presente na fala de 14 dos estudantes respondentes. Dentre os entrevistados que confirmam o fato estão: o EST/EJA 2 que disse: "O livro ajuda a aprender a ler e a escrever.", seguido da EST/EJA 4 que falou: "Pra" ajudar "agente" a aprender." e do EST/EJA 9 que afirmou que: "O livro pode ajudar a aprender a ler e a escrever."

Um total de sete alunos se expressaram em relação ao LD como sendo um direito que lhes foi negado. Destes cito: o EST/EJA 7:" Porque é um direito nosso e faz falta "pragente" aprender e arrumar trabalho.", seguido dos EST/EJA 3,8 e 14: "Porque é um direito nosso que não temos." 


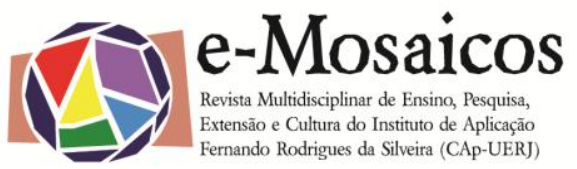

DOI: $10.12957 /$ e-mosaicos.2018.38651

Apesar de desejarem ter o LD por diversas razões já expressadas, 15 alunos pontuaram a dificuldade de trabalhar com este material, aliás, dificuldade essa cuja possibilidade a experiência em turmas de EJA já me haviam permitido inferir. Contudo, é sabido que apenas cinco alunos da IE3, de um universo de 24 respondentes, receberam o livro didático "EJA Moderna" Volume I o que não corresponde ao número total de evocações para a subcategoria "difícil/dificuldade". O que acontece é que nas outras turmas as professoras apresentaram outros livros didáticos, os quais não atenderam as necessidades de aprendizagem dos alunos, também pelo grau de dificuldade dessas obras. Na escola citada acima (IE3), a única a receber o livro didático adotado pela SEMED, os alunos se posicionaram da seguinte maneira: o EST/EJA 20 disse que: "O livro pode ajudar "agente a ler $e$ a escrever com ajuda da professora.", o EST/EJA 21 pontuou que: "O livro é muito difícil.", o EST/EJA 22, por sua vez, afirmou que: "Não dá "pra" fazer o dever no livro sozinho.", o EST/EJA 23 justificou dizendo que: "Porque é difícil de fazer as atividades sem ajuda da professora." e, por último, a EST/EJA 24 ponderou: "Porque preciso de ajuda "pra" fazer o dever do livro."

Tais justificativas dos alunos a respeito das dificuldades encontradas nos materiais didáticos em uso na sala de aula, e principalmente em relação à obra adotada, são corroboradas pelas observações de vários autores que tratam da temática Material Didático para a EJA adequado às necessidades de aprendizagem desses estudantes, bem como a preocupação com um currículo adequado às suas especificidades. Nesse sentido, o livro didático a ser usado com esse público deve dialogar com o contexto social desses educandos para que o ensino-aprendizagem efetivamente ocorra.

De acordo com MELLO (2010), é preciso não perder de vista a questão da diversidade dos atores (estudantes e professores) da EJA. Ao escolher os materiais didáticos direcionados a esses alunos, o autor pontua entre outros aspectos que, fazse necessário considerar o quão heterogêneo social e culturalmente é esse público e como diversas são as formas e os ritmos de sua aprendizagem, para que se possa, efetivamente, selecionar e organizar de forma significativa os conteúdos de aprendizagem para essa modalidade "incluindo temas e abordagens que levem em consideração a rede de experiências e aprendizagens que jovens e adultos construíram em suas trajetórias de vida" (MELLO, 2010, p. 96).

As respostas dos alunos da EJA deixam claro que apesar da ausência do Livro Didático, nas turmas de duas das três escolas nas quais a pesquisa foi realizada, tal material representa para esses alunos a possibilidade dos mesmos obterem êxito na aquisição dos conhecimentos relacionados ao seu grupo/fase de escolaridade, como é possível observar nas justificativas dos alunos participantes da pesquisa relacionadas à questão " $O$ que vem a sua mente quando você ouve a seguinte expressão: O Livro Didático da EJA pra você é...". Tal pergunta obteve por parte dos alunos respostas em que palavras como importante (13), necessidade/necessário (7) foram evocadas demonstrando que mesmo na maior 
DOI: $10.12957 /$ e-mosaicos.2018.38651

parte das vezes o livro não atendendo às necessidades dos alunos e dos professores, constitui-se numa importante ferramenta, pois representa para esses sujeitos 0 acesso a um bem que lhes pertence por direito. Se, por um lado, o LD EJA Moderna, volume I, é uma obra que faz parte do Programa Nacional do Livro Didático para a Educação de Jovens e Adultos (PNLD/EJA) e, consequentemente por ser adotada pela Secretaria Municipal de Educação do Município de São Gonçalo (SEMED/SG) o aluno deveria ter o acesso a esse material didático o que, de fato, nas duas escolas pesquisadas não aconteceu por razões que desconhecemos.

A respeito da pergunta "Você sente dificuldade no uso do livro didático?" as respostas mostram que num universo de 24 alunos a categoria ajuda foi mencionada 19 vezes, seguida das categorias difícil/dificuldade queforam citadas 15 vezes. Mesmo os alunos da IE3, os quais, segundo a professora da turma afirma terem recebido o Livro Didático EJA Moderna, volume I, em suas respostas deixam claro que o livro é muito difícil e que o mesmo pode vir a ajudar na leitura e na escrita, desde que a professora da turma possa auxiliá-los nas atividades. Ao final, é possível perceber que na visão do aluno mesmo não tendo recebido o LD este, segundo as informações coletadas, é considerado um recurso importante", "necessário" e acima de tudo, um "direito" que Ihe foi negado.

$\mathrm{Na}$ única escola (IE3) onde os alunos receberam o livro didático os mesmos se referiram à dificuldade de trabalhar com um material complexo e distante de suas realidades. Sobre o papel desempenhado pelo LD na efetividade do processo educativo, Bittencourt (2003) afirma que "como um dos instrumentos de trabalho dos professores e alunos torna-se necessário entendê-lo em todas as dimensões $e$ complexidade"(BITTENCOURT, 2003, p. 16).

Mesmo tendo sido um instrumento exploratório, a análise das palavras evocadas, uma vez associada aos depoimentos coletados no questionário, leva-nos a inferir que existe uma representação social sobre o Livro Didático. Apesar do mesmo não ter sido distribuído aos alunos das outras duas escolas pesquisadas - 19 dos 24 estudantes pesquisados não tiveram acesso ao livro do PNLD/EJA, ainda assim foi possível perceber o valor social que o livro didático representa para esses alunos. 0 resultado dessa pesquisa demonstrou que o livro didático pela sua importância, apesar de não ser o único instrumento capaz de efetivar a aprendizagem dos alunos, acaba sendo o único recurso de que os mesmos dispõem no cotidiano da sala de aula e, por essa razão para que o LD cumpra efetivamente o seu papel de formação e informação é necessário que os conteúdos nele presentes estejam contextualizados de acordo com o contexto social do aluno.

\section{CONSIDERAÇÕES FinAIS}

A pesquisa realizada possibilitou reconhecer a importância do livro didático para o estudante da modalidade Educação de Jovens e Adultos. Mais do que um direito estabelecido pelo PNLD/EJA, ter o livro didático representa o direito a ter um 
DOI: $10.12957 /$ e-mosaicos.2018.38651

livro, pois não são raras as vezes em que este é o único livro a que o estudante tem acesso.

As expressões evocadas a partir do termo indutor "O Livro Didático da EJA pra você é...": "ajuda, recurso bom, para aprender a ler, difícil, importante ter, necessário, direito, melhorar a escrita, ajuda pra aprender a ler e escrever, não tenho, bom, não ganhei", seguidas de algumas das justificativas "Porque ter o livro é um direito nosso", "O livro ajuda a aprender a ler e a escrever", permitem-nos inferir que os estudantes atribuem um valor social positivo a um instrumento que, no caso do grupo estudado, nem sempre chegou às suas mãos. A pesquisa revelou, também, o entendimento de um direito inalienável, dentre outros, que lhes foi negado.

Diante do exposto e considerando o recorte feito neste artigo, a pesquisa revelou que o fato do governo federal manter a política pública do livro didático não e suficiente. Mais do que produzir, avaliar e distribuir materiais didáticos suprindo assim as escolas com esse importante instrumento de trabalho e de consulta, é preciso e urgente atentar para a necessidade de monitoramento no que se refere ao acompanhamento de usos e à avaliação desse material.

Em um país das dimensões do Brasil, o uso do livro didático precisa contemplar a diversidade que perpassa cada região do país e trazer para suas páginas as muitas caras dos jovens e adultos brasileiros.

\section{REFERÊNCIAS BIBLIOGRÁFICAS}

ABRIC, Jean-Claude. O estudo experimental das representações sociais. In: JODELET, Denise. As representações sociais. Rio de Janeiro: EdUERJ, 2001. p. 155171.

BARDIN, L. Análise de conteúdo. Lisboa: Edições 70, 225 p., 2002.

BITTENCOURT, C. M. F.. Em foco: história, produção e memória do livro didático. In: Educação e Pesquisa. v. 30, n. 3. São Paulo: Set/2003.

FERNANDES, A. da P. Memórias e representações sociais de jovens e adultos: lembranças ressignificadas da escola da infância e expectativas no retorno à escola. Tese (Doutorado). Campinas: UNICAMP, 2012.

FRANCO, M. L. P. B. Representações Sociais, Ideologia e Desenvolvimento da 
DOI: $10.12957 /$ e-mosaicos.2018.38651

Consciência. In: Cadernos de Pesquisa, v. 34, n.121, p. 169-186, jan./abr. 2004.

FREIRE, P. Professora sim, tia não: Cartas a quem ousa ensinar. Editora Olho D'água. $10^{a}$ ed., p. 27, São Paulo: 1993.

MELLO, P. E. D. Material Didático para Educação de Jovens e Adultos: história, formas e conteúdos. Tese (Doutorado). São Paulo: FEUSP, 2010.

Disponível em:http://www.teses.usp.br/teses/disponiveis/48/48134/tde-26012011142038/pt-br.php. Acesso em:16 jul. 2014.

RONDELLI, E. Material didático: interatividade é fundamental. Disponível em: <http://www.ead.sp.senac.br/newsletter/novembro06/mercado/mercado.htm>. Acesso em: 20 mai.2014.

Recebido em 14 de Agosto de 2017 Aceito em 30 de Agosto de 2018 